\title{
Nature Inspired Algorithms as a Tool for Diseased Millets Leaf Segmentation
}

\author{
Pavithra P, Aishwarya P
}

\begin{abstract}
Agriculture is the main occupation undertaken by majority of population in India. The Indian farmers produce food grains for entire population. Growing population needs constant increase in quantity and quality of agriculture produce. This is possible only by adopting improved technology in production and plant protection. Hence, technology intervention is at every stage of production and food processing is needed. Timely and suitable plant protection measures directly improve quantity and quality of agriculture produce. Effective result oriented plant protection mainly involves early detection of pest and diseases and suitable control measures. The entire human population consume products of food grains like cereals and millets as their staple food. This paper aims at summarizing common image processing methods to identify plant diseases and how it could be improved using nature inspired algorithm.
\end{abstract}

Keywords - Agriculture, Image Processing, Leaf diseases, Millets, Nature Inspired Algorithms

\section{INTRODUCTION}

Plants mainly consist of leaves and supporting stem. Leaves, where photosynthesis is done, produce food for plant growth. When leaves are damaged due to diseases the plant growth is directly affected resulting in reduction in final yield. In traditional farming, in earlier days, the farmers used to detect the diseases only by observing and feeling the symptoms, that too at an advanced stage which resulted in heavy loss in yield. To meet increase in demand for food grain, the production is increases by growing technologically improved new varieties of plants. The farming has become more commercial which requires effective modern production technology. One of such technologies is early plant disease detection and control. Research on leaf diseases in pathology lab give information on the causes of disease and remedies that would control the disease. This pathological research data can be used to develop technology which can detect the disease by machine vision. Sample images of the diseased leaves at various stages are captured and subjected to texture analysis. Machine learning is applied to detect the image patterns and this data can further be used to train the system for leaf disease detection. A lot of work has been done in the field of image processing for technologically guided agriculture, including weed detection, fruit classification, quality evaluation, pest detection and disease estimation.

Revised Manuscript Received on February 05, 2020.

* Correspondence Author

Pavithra P, Research scholar, Atria Institute of Technology, Bangalore, India. Email: pavithraperumal@gmail.com,

Dr. Aishwarya P, Professor, Department of CSE, Atria Institute of Technology, Bangalore, India. Email: aishwarya.p@atria.edu

(C) The Authors. Published by Blue Eyes Intelligence Engineering and Sciences Publication (BEIESP). This is an open access article under the CC BY-NC-ND license (http://creativecommons.org/licenses/by-nc-nd/4.0/)

This paper is organised as follows: section II give information about millets and the common disease that affect production of grains. Section III contains the image processing methods used in modern agriculture mainly with the diseases identification. Section III summarises some of the applications of Nature Inspired Algorithm on real world problems. Section IV suggests how the Nature Inspired Algorithms could be used with image processing for more reliable disease detection.

\section{MILLETS AND THEIR COMMON DISEASE}

Millets form the most important cereal in the world food for humans and animal fodder. They are characterised by hard small sized seed. Millet is staple food for majority of the people in under-developed and developing countries of Asia and Africa. Most commonly grown millets in India are pearl millet, finger millet, sorghum and foxtail millet. Millets are gaining popularity for its nutritional values and studies have proven that consumption of millets lower the risk of diseases caused by blood pressure, fat absorption and gastric emptying. TABLE 1 show that the millets have higher protein content that the most commonly consumed cereals, rice and wheat [1].

Table 1 Common Cereal and their Nutritional Values (per 100gm edible portion with $12 \%$ moisture)

\begin{tabular}{|c|c|c|c|c|c|c|}
\hline Cereal & $\begin{array}{l}\text { Scientifi } \\
\text { c Name }\end{array}$ & $\begin{array}{l}\text { Indian } \\
\text { Name }\end{array}$ & $\begin{array}{l}\text { Carbo } \\
\text { hydrat } \\
\text { e(g) }\end{array}$ & $\begin{array}{l}\mathrm{Ca} \\
(\mathrm{m} \\
\mathrm{g})\end{array}$ & $\begin{array}{l}\text { Fe } \\
\text { (mg) }\end{array}$ & $\begin{array}{l}\text { Protei } \\
\mathrm{n}(\mathrm{g})\end{array}$ \\
\hline $\begin{array}{l}\text { Brown } \\
\text { rice }\end{array}$ & $\begin{array}{l}\text { Oryza } \\
\text { sativa }\end{array}$ & $\begin{array}{l}\text { Chaaval, } \\
\text { Arisi }\end{array}$ & 76.0 & 33 & 1.8 & 7.9 \\
\hline Wheat & $\begin{array}{l}\text { Triticum } \\
\text { aestivum }\end{array}$ & $\begin{array}{l}\text { Gehoon, } \\
\text { Godhima } \\
\text { i }\end{array}$ & 71.0 & 30 & 3.5 & 11.9 \\
\hline Maize & $\begin{array}{l}\text { Zea } \\
\text { mays }\end{array}$ & $\begin{array}{l}\text { Makka, } \\
\text { Makka } \\
\text { solam }\end{array}$ & 73.0 & 26 & 2.7 & 9.2 \\
\hline $\begin{array}{l}\text { Pearl } \\
\text { millet }\end{array}$ & $\begin{array}{l}\text { Penniset } \\
\text { um } \\
\text { glaucum }\end{array}$ & $\begin{array}{l}\text { Bhajra, } \\
\text { Kambu }\end{array}$ & 67.0 & 42 & 11 & 11.8 \\
\hline $\begin{array}{l}\text { Finger } \\
\text { millet }\end{array}$ & $\begin{array}{l}\text { Eleusine } \\
\text { coracana }\end{array}$ & $\begin{array}{l}\text { Manduv } \\
\text { a, } \\
\text { Kelvargu } \\
\text { ', } \\
\text { Ragi }\end{array}$ & 72.6 & $\begin{array}{l}35 \\
0\end{array}$ & 3.9 & 7.7 \\
\hline $\begin{array}{l}\text { Foxtail } \\
\text { millet }\end{array}$ & $\begin{array}{l}\text { Setaria } \\
\text { italic }\end{array}$ & $\begin{array}{l}\text { Kangni, } \\
\text { Tenai }\end{array}$ & 63.2 & 31 & 2.8 & 11.2 \\
\hline $\begin{array}{l}\text { sorghu } \\
\text { m }\end{array}$ & $\begin{array}{l}\text { Sorghu } \\
\text { m } \\
\text { bicolour }\end{array}$ & $\begin{array}{l}\text { Jowar, } \\
\text { Solam }\end{array}$ & 70.7 & 25 & 5.4 & 10.4 \\
\hline
\end{tabular}




\section{Nature Inspired Algorithms as a Tool for Diseased Millets Leaf Segmentation}

Millets require less or no irrigation as it can grow in too hot and dry climatic conditions. Millets are poor farmers' choice of crops for two main reasons, lower cost of production and great nutrition values.

India produces about $42.08 \%$ of the world's pearl millet[2]. It covers 10 million hectares of the agricultural land. But this crop also has records of major yield loss. The major factor for loss in crop is the diseases caused by microorganisms, parasitic and non-parasitic weeds, insects and birds. Totally 111 different diseases have been reported on the most important millet, the pearl millet in Africa and India. Among these diseases, downy mildew(green-ear disease), Smut, Ergot, Rust and Blast are the most reported fungal diseases[3].

Downy mildew the symptoms of this disease are visible on leaves and ear head of the affected plant. The leaves starts to turn into yellow from the lower end of the leaf or the ear head would produce a leaf-like structure giving the name 'green-ear'. This disease will lead to stunted growth and does not produce ear head. Leaf Blast disease symptoms includes lesions of elliptical or diamond shapes with gray centres on the leaf. Neck blast have lesions are elongated and black and appear below the ear head. Rust disease is associated with pustules that are reddish brown giving a 'rusty' look to the leaves. This symptom starts to appear from the lower leaves of the plant and spread to young leaves on top. Smut disease is developed by infected ovary and grows into a grain like large structure sorus in place of the grain in the head[4]. Ergot disease symptoms are seen on the ear heads with sugary viscous liquid coming out of the glumes and leads to black scleotia developing in place of grain[3].

\section{LEAF DISEASE DETECTION METHODS}

Image processing and machine vision researchers have done enormous contribution to provide easy and cost effective methods of leaf disease detection. Researchers have suggested various methods for the same. The authors of [5] paper have presented a review on techniques for disease classification. The authors have proposed a genetic based algorithm for segmentation. They have used colour cooccurrence matrix for feature extraction and genetic algorithm for clustering in to $\mathrm{K}$ clusters. The proposed technique was tested on various plant species and various diseases. The result obtained was 93.63\% accurate. In paper [6], a non destructive method of Quality evaluation of rice grains using computer vision is proposed. Images of rice are converted to grey scale and morphological operations are performed to identify relevant parts of the rice. Threshold is computed based on histogram and the rice quality is evaluated. Paper [7] proposes a method for automatic estimation of coffee leaf damage. The leaf image is preprocessed by performing gamma correction. It is then converted to YUV colour space and Fuzzy C-means is used for clustering in the $\mathrm{V}$ space. The leaf damage is estimated as ratio of the normal pixels to the defected portion. The proposed method was estimated to be better than the other methods compared and naked eye inspection.

In paper [8] Colour Co-occurrence Matrix(CCM) is used on HIS colour model, 39 texture features were obtained in $\mathrm{H}, \mathrm{S}$ and I. These features were grouped into different models and were used to classify into 4 disease categories. Stepwise linear reduction process was used to reduce the number of features for each category. The results showed that the texture features based Hue and Saturation gave better results than the intensity based features. This model was tested on 20 samples of each category and the result obtained was 95\% accurate.

The authors of [9] used colour texture feature to mask the normal green colour of the leaf and segment the diseased part of the leaf. The image is initially converted to HIS and then segmented. The authors of [10] have described various diseases commonly affecting cotton leaves, and the general methodology followed for processing leaf images for disease detection. The paper also describes the commonly used features for extraction. The authors[11] have worked on cotton leaves affected by pests and insects. The images were pre-processed and segmented by using Spatial Fuzzy C-means algorithm. The colour features are extracted from the segmented images and then the disease is classified by Probabilistic Neural Network classifier. The authors in [12] have reviewed various papers and have given the general method followed for plant leaf disease detection.

The authors in paper[13] have reviewed the various image processing methods for feature extraction and classification of images. They have also given the general methodology followed for leaf disease detection using image processing. Researchers have explored the Colour texture analysis $[9,10]$ and colour models[7,8] for detecting leaf disease. Fuzzy logic, neural network and machine learning have been applied to learn about the patterns of diseases[11,12].

The authors of paper[14] described regression based methods for leaf rust disease detection on wheat plant leaves. Experiments were conducted using Partial Least Square Regression (PSLR), support Vector Regression(SVR), v-Support Vector regression( $v$-SVR), and Gaussian process regression (GPR). The paper [15] describes a simple method for leaf-spot disease detection in sugarcane plants. The leaves were segmented using thresholding method in $\mathrm{L}^{*} \mathrm{a} * \mathrm{~b}$ color space and maximum standard deviation was applied to detect the diseased spot. The type of disease detected uses Gray-Level Co-occurrence Matrix(GLCM). Authors of paper[16] proposed a novel method of feature extraction based on local descriptors and Bag- of-visual Words(BOVW). Since the local descriptors do not require the image to be segmented, the method is more robust. The proposed model had three phases: feature extraction, vocabulary construction, histogram of visual word occurrence. The Paper[17] describes a SVM based classifying method of disease recognition in grape leaf. This method followed a simple process: segmentation by Kmeans clustering, feature extraction - 18 texture features were extracted and stored in data base for training. SVM was used to classify the testing images. 
The authors in paper [18] have worked on the three different colour spaces for disease identification. The captured image was converted to CIELab, YCbCr and HSV image and processed parallel. The images were enhanced and morphological operations were performed on the three images and texture features distance matrices were obtained and then the infected regions were extracted.

The paper[19] presents review of the common methodologies followed to detect leaf disease. The paper[20] suggests a method to extract cucumber leaf spots in a complex background. Water-marked algorithm is used to extract the leaf of interest from the background; neighbourhood greyscale information is used for segmentation of cucumber spot edges. This paper[21] presents another method for cucumber leaf disease detection using global-local Singular Value Decomposition(SVD). First, watershed algorithm is applied to segment the image. Second, the leaf spots image is decomposed to obtain Global-Local singular values. Third, keypoint features are extracted. Finally, SVM is used to classify the diseased leaf. The [22] paper presents a novel method for disease detection using color information and region growing. Comprehensive Colour Feature(CCF) is used to separate foreground from cluster background. Region growing method of segmentation is performed on the CCF map and morphological operations are performed to refine the results.

The [23] paper proposes a new method based on global and zone-based local features to detect bacterial disease citrus canker on citrus leaves. The algorithm works on the images captured in the field, hence required background and forground separation which is done by AdaBoost algorithm. The image is divided into different zones and features are extracted and they are fused to differentiate the lesions caused by canker and others.

Authors of [24] presents a method for detecting and estimating the severity of bacterial spot disease on tomato leaf. Visual spectrum images were pre-processed for brightness and size adjustment and then converted to CIELab image. The paper[25] presents a method to recognise the Bakanae disease in the rice plant. The rice plant image is captured and anatomical parts of the plant are recognised, measured and classified. First, the morphological opening and thinning is performed in rice seedling image to obtain the skeleton of the image and the lengthwise and width wise end points are measured. And the colour trait, hue is measured. Second, Principal Component Analysis (PCA) is performed. Third, SVM is sued to classify the healthy and non-healthy rice seedling.

The paper[26] proposes a method for early detection and identification of three types of diseases(leaf spot , leaf rust and powdery mildew) on Sugar beet leaf. The proposed method uses SVM and spectral vegetative indices. The accuracy was achieved higher than 86\%. The paper[27] proposes SVM based method to detect borer disease in sugarcane. First the image is segmented by thresholding and morphological filling and corrosion operations are performed on it. Adaptive thresholding was used to find the minimum grey value and the average minimum grey value was as classification feature. Finally SVM was used to classify the images.

The[28] paper proposes a method for detecting powdery mildew and Tomato Spotted Wilt Virus (TSWV) diseases in bell pepper plants. RGB channels were used to classify each pixel as healthy $\mathrm{r}$ non- healthy using PCA method. Additionally, Coefficient of Variation (CV) was explored over the RGB channels for TSWV detection. Paper [29] presents a simple method of disease detection in brinjal leaf. First, the image is enhanced by histogram equalization, construct color transformation structure, apply $\mathrm{K}$ - means clustering, convert the affected leaf from RGB to HIS format, generates spatial grey level dependence matrices for $\mathrm{S}$ and $\mathrm{H}$ dimension. Then the GLCM is computed for extracting the texture features. Artificial Neural Network is used for training and recognising the leaf disease.

The paper [30] provides a simple method of jujube plant disease identification. Firstly, the images were thresholdsegmented to separate foreground and background; secondly, colour and texture features were extracted. Colour, morphological and texture feature models were selected and tested to distinguish healthy and unhealthy leaves affected by six types of diseases. Each feature set was evaluated by cross-validation classification. Analysis of the contribution of each feature set to the PCA was also performed. ANN with two-layered network and one hidden layer was applied with 12 neurons for 12 selected features and 6 output neurons. The images were classified into six diseases with minimum of $73 \%$ and maximum of $94 \%$ accuracy.

\section{IV.CONTRIBUTION OF NIA ALGORITHMS}

Natural systems have affected our lives in many ways. We look at nature as the universal solution provider for all problems with no known solution. Among the physical, chemical and biological aspects of nature we are greatly influenced by the biological aspects such as how the animals search for food, how they communicate the availability of food to fellow beings, how they defend themselves from their enemies and how they travel from one place to another in a swarm. Some of the algorithms developed based on these phenomenon are Artificial Bee Colony(ABC), Ant Colony Optimisation(ACO), Bat Algorithm(BA), Fish Swarm Algorithm(FSA), Whale Optimisation Algorithm(WOA), Flower Pollination Algorithm(FPA), Artificial Algae Algorithm(AAA), Fireflies Algorithm, Cuckoo Search Algorithm(CSA), Cat Swarm Optimisation(CSO), Chicken Swarm Optimisation Algorithm (CSOA), Grey Wolf Optimisation(GWO).

Bio inspired algorithms are applied to mostly solve optimization problems. They are proven to be better solutions than other conventional methods. Most of the image processing techniques need real time results. Segmentation, image fusion, texture analysis are time consuming processes. Hence, applying nature-inspired algorithms for these processes would yield faster and more accurate results.

The authors of [31] have summarized NIA for real-world optimization problems including power distribution, short term scheduling problem and design of Ultra Wide band (UVB) with better accuracy and fast convergence. 


\section{Nature Inspired Algorithms as a Tool for Diseased Millets Leaf Segmentation}

Moth-flame Optimization (MFO) was used by the authors of [32] to automatically detect powdery mildew and early blight diseases of tomato.

The proposed method was more efficient than the Partial Swarm Optimisation (PSO) and Genetic Algorithm (GA). Paper [33] describes in detail some of the recently developed NIA including ABC, FSA, CSO, CSOA, WOA, $\mathrm{MFO}, \mathrm{GWO}$ and their possible application for real world problem.

Paper [34] uses ABC to select feature set for grape leaf disease identification. The feature set is then given to SVM for classification of the leaf disease.

Paper [35] uses Ant Colony Optimisation technique to optimise disease classification with SVM. Paper [36] uses spider monkey optimization to filter out insignificant features and optimise the feature set for disease identification. It later uses SVM to predict the disease.

\section{PROPOSED METHODOLOGY}

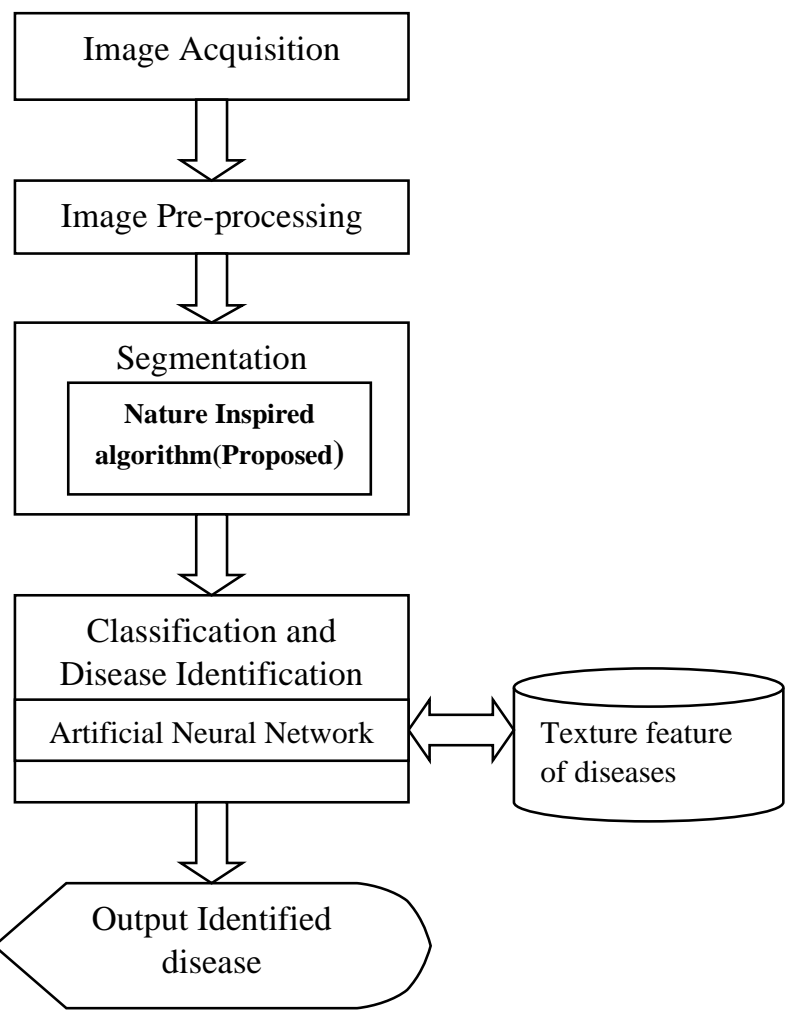

Figure 1: Methodology for disease identification

Researchers have applied various image processing techniques for disease identification of the crops. The most crucial part of the process in image segmentation, here we propose a methodology that uses Nature Inspired Algorithms to segment the images more accurately and efficiently.

\section{RESULT}

In general sample leaves are collected and are subjected to image pre-processing techniques to eliminate noise in the image and enhance the foreground to ease further processing. The image is then segmented by edge detection and NIA. For experiment, the image was segmented by Sobel edge detection and ABC, a NIA. The result showed that the segmentation by $A B C$ algorithm showed the diseased part of the image more accurately than the edge detection.

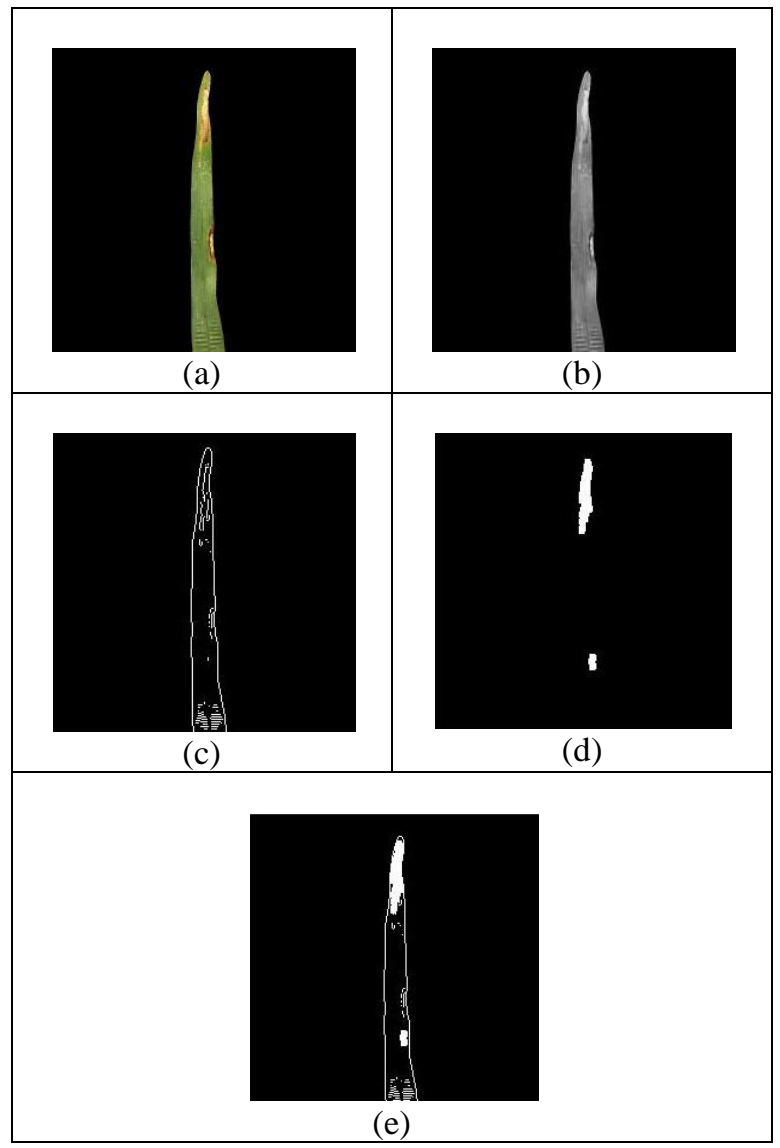

Figure 2:Input and Output of image segmentation: (a) Input image in RGB format;(b) Input image in greyscale; (c) Segmented by Sobel edge detection ; (d) Segmented by ABC;(e) fusion of ABC and Sobel segmented image.

\section{CONCLUSION}

It is observed that image segmentation and analysis of the segmented image is the most complicated and crucial part of leaf disease identification. Incorrect and inaccurate segmentation of the disease area of the image could lead to wrong diagnosis and treatment for the crops. Improving the process's accuracy will help in reducing false identification. Although Nature inspired algorithms are complicated, they have proven to give optimal solution for problems. In today's world, computer resources come with high computational capabilities that can easily run such complicated algorithms. Millet diseases such as leaf blast and leaf rust have visible symptoms on leaf. Hence, including nature inspired algorithms in the process of leaf diseases identification of millets would make the results more reliable and reduce failure of crops. 
Image acquisition methods - digital cameras, mobile phone cameras

Color models - HIS, RGB, Grey scale , YUV, $L * a * b *$.

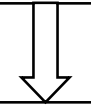

Pre-processing methods -

Enhancement- Histogram equalisation, Contrast - Gamma correction

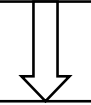

Segmentation methods

Thresholding, green pixel masking,

Edge detection

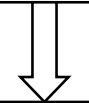

Feature extraction methods - GLCM, GLRLM, CCM, Gabor Filters

Feature selection methods- MFO, Rough set

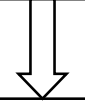

Classification methods-

$\mathrm{SVM}, k-\mathrm{NN}$, multiple linear regression models

Figure 3: General methods followed for disease identification by image processing

\section{REFERENCES}

1. Ahmed S.M. Saleh, Qing Zhang, Jing Chen, and Qun Shen, Millet Grains: Nutritional Quality, Processing, and Potential Health Benefits, Comprehensive Reviews in Food Science and Food Safety, Vol.12, 2013, 281-295.

2. Kumara Charyulu D, Bantilan C, Rajalaxmi A, Rai KN, Yadav OP, Gupta SK, Singh NP and Moses Shyam D, Development and Diffusion of Pearl Millet Improved Cultivars in India: Impact on Growth and Yield Stability. Working Paper Series No. 52, International Crops Research Institute for the Semi-Arid Tropics. 2014, 76.

3. Arun Kumar, Diseases of Pearl Millet and their Management, Plant Health and their Management(P. C. Trivedi Eds.) Agrobios (India): 2011, 33-45

4. IK Das, A Nsagaraja, Vilas A Tanopi, Disease of Millets a ready reckoner, ICAR-Indian Institute of Millets Research, ISBN: 81-8933559-6

5. Vijai Singh , A.K. Misra, Detection of plant leaf diseases using image segmentation and soft computing techniques, Elsevier -Information, Processing in Agriculture 4 , 2017, 41-49

6. Chetna V. Maheshwari, Machine Vision Technology For Oryza Sativa L.(Rice), International Journal of Advanced Research in Electrical, Electronics and Instrumentation Engineering Vol. 2, Issue 7, July 2013

7. Eric Hitimana and Oubong Gwun, "Automatic Estimation of Live Coffee Leaf Infection Based on Image Processing Techniques" Second International Conference on Signal, Image Processing and Pattern Recognition,Sydney, Australia, , 2014, pp 42215

8. R. Pydipati, T.F. Burks , W.S. Lee, Identification of citrus disease using color texture features and discriminant analysis, Elsevier Computers and Electronics in Agriculture 52,(2006, 49-59

9. Prof. Sanjay B. Dhaygude, 2Mr.Nitin P.Kumbhar, Agricultural plant Leaf Disease Detection Using Image Processing, International Journal of Advanced Research in Electrical, Electronics and Instrumentation EngineeringVol. 2, Issue 1, 2013, 599-602

10. Bhumika S.Prajapati, Vipul K.Dabhi, Harshadkumar B.Prajapati, A Survey on Detection and Classification of Cotton Leaf Diseases, International Conference on Electrical, Electronics, and Optimization Techniques (ICEEOT) , 2016, 2499-2506

11. Premalatha.V, Valarmathy.S, Sumithra.M.G, Disease Identification in Cotton Plants Using Spatial FCM \& PNN Classifier, International Journal of Innovative Research in Computer and Communication Engineering, Vol. 3, Issue 4, 2015, 3195-3201

12. Varsha Sawarkar, Seema Kawathekar, A Review: Rose Plant Disease Detection Using Image Processing, IOSR Journal of Computer Engineering (IOSR-JCE), Volume 20, Issue 4, Ver. III, 2018, PP 15-19

13. Priyanka L Kumble, Anjali C Pise, Review On Agricultural Plant Disease Detection By Using Image Processing , International Journal of Latest Trends in Engineering And Technology, Vol 7 Issue 1, 2016, pp 335-339

14. Davoud Ashourloo, Hossein Aghighi, Ali Akbar Matkan, Mohammad Reza Mobasheri, and Amir Moeini Rad, An Investigation Into Machine Learning Regression Techniques for the Leaf Rust Disease Detection Using Hyperspectral Measurement, IEEE Journal Of Selected Topics In Applied Earth Observations And Remote Sensing, Vol. 9, No. 9, 2016, 4344-4351

15. Evy Kamilah Ratnasari, Mustika Mentari, Ratih Kartika Dewi, R. V. Hari Ginardi, Sugarcane Leaf Disease Detection and Severity Estimation Based On Segmented Spots Image, IEEE: 2014 International Conference on Information, Communication Technology and System, 2014, 93-98

16. Rillian Diello Lucas Pires, Diogo Nunes Gonçalves, Jonatan Patrick Margarido Oruê , Wesley Eiji Sanches Kanashiro , Jose F. Rodrigues Jr. , Bruno Brandoli Machado ,Wesley Nunes Gonçalves, Local descriptors for soybean disease recognition, Elsevier: Computers and Electronics in Agriculture 125, 2016. 48-55

17. Pranjali B. Padol, Anjali A. Yadav, SVM Classifier Based Grape Leaf Disease Detection, IEEE: 2016 Conference on Advances in Signal Processing (CASP), 2016, 175-179

18. Tallha Akram, Syed Rameez Naqvi , Sajjad Ali Haider, Muhammad Kamran, Towards real-time crops surveillance for disease classification: exploiting parallelism in computer vision, Elsevier: Computers and Electrical Engineering 59, 2017, 15-26

19. Vishnu S, A. Ranjith Ram, Plant Disease Detection Using Leaf Pattern: A Review, International Journal of Innovative Science, Engineering \& Technology, Vol. 2 Issue 6, 2015.

20. Xuebing Bai, Xinxing Li, Zetian Fu, Xiongjie Lv, Lingxian Zhang, A fuzzy clustering segmentation method based on neighbourhood grayscale information for defining cucumber leaf spot disease images, Elesvier: Computers and Electronics in Agriculture 136, 2017, 157165

21. Hanwen Zhang, Zhen Wang, Cucumber Disease Recognition Based on Global-Local Singular Value Decomposition, Elsevier: Neurocomputing 205, 2016, 341-348

22. Juncheng Maa, Keming Du , Lingxian Zhang , Feixiang Zheng Jinxiang Chu , Zhongfu Sun, A segmentation method for greenhouse vegetable foliar disease spots images using color information and region growing, Elsevier: Computers and Electronics in Agriculture 142, 2017, 110-117

23. Min Zhang, Qinggang Meng, Automatic citrus canker detection from leaf images captured in field, Elsevier: Pattern Recognition Letters 32, 2011, 2036-2046

24. Díbio L. Borges, Samuel T.C. de M. Guedes, Abadia R. Nascimento, Pedro Melo-Pinto, Detecting and grading severity of bacterial spot caused by Xanthomonas spp. in tomato (Solanum lycopersicon) fields using visible spectrum images, Elsevier: Computers and Electronics in Agriculture 125, 2016, 149-159

25. Chia-Lin Chung, Kai-Jyun Huang , Szu-Yu Chen , Ming-Hsing Lai , Yu-Chia Chen , Yan-Fu Kuo, Detecting Bakanae disease in rice seedlings by machine vision, Elsevier: Computers and Electronics in Agriculture 121, 2016, 404411 
26. T. Rumpfa, A.K. Mahleinb, U. Steinerb, E.C. Oerkeb, H.W. Dehneb, L. Plümera, Early detection and classification of plant diseases with Support Vector Machines based on hyperspectral reflectance, Elsevier: Computers and Electronics in Agriculture 74 ,2010, 91-99

27. Tisen Huang, Rui Yang , Wenshan Huang , Yiqi Huang , Xi Qiao, Detecting sugarcane borer diseases using support vector machine, Elsevier: Information Processing in Agriculture 5, 2018, 74-82

28. Noa Schor, Avital Bechar, Timea Ignat, Aviv Dombrovsky, Yigal Elad, Sigal Berman, Robotic Disease Detection in Greenhouses: Combined Detection of Powdery Mildew and Tomato Spotted Wilt Virus, IEEE Robotics and Automation Letters, Vol. 1, No. 1, 2016, 354-356

29. Anand R,Veni S,Aravinth J, An Application of image processing techniques for Detection of Diseases on Brinjal Leaves Using K-Means Clustering Method, IEEE: 2016 Fifth International Conference On Recent Trends In Information Technology, 2016, 1-5

30. Weidan Zhang, Guifa Teng , Chunshan Wang, Identification of jujube trees diseases using neural network, Elsevier: Optik 124, 2013, 1034 1037

31. Wei Fang, Xiaodong Li, Mengjie Zhang, Mengqi Hu, Nature-Inspired Algorithms for Real-WorldOptimization Problems, Hindawi Publishing Corporation Journal of Applied Mathematics Volume 2015, Article ID 359203, 2015

32. Aboul Ella Hassanien, Tarek Gaber, Usama Mokhtar, Hesham Hefny, An improved moth flame optimization algorithm based on rough sets for tomato diseases detection, Elsevier: Computers and Electronics in Agriculture 136, 2017, pp 86-96

33. Ashraf Darwish, Bio-inspired computing: Algorithms Review, Deep Analysis, and the Scope of Applications, Future Computing And Informatics Journal 3, 2018, 231-246

34. Andrushia, A. \& Trephena, Patricia. Artificial bee colony optimization (ABC) for grape leaves disease detection, Evolving Systems, Springer, 2019, 1-13.

35. Iqbaldeep Kaur, Gifty Aggarwal and Amit Verma, Detection and Classification of Disease Affected Region of Plant Leaves using Image Processing Technique, Indian Journal of Science and Technology, Vol 9, 48, 2016, 1- 13

36. Sandeep Kumar, Basudev Sharma, Vivek Kumar Sharma, Harish Sharma, Jagdish Chand Bansal, Plant Leaf Disease Identification using Exponential Spider Monkey Optimization, Sustainable Computing: Informatics and Systems, 2018, 1-24

\section{AUTHORS PROFILE}

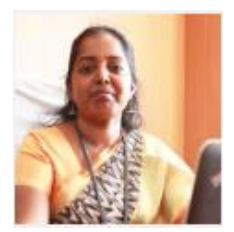

Dr. Aishwarya. P has secured gold medal in B.E from Bharathidasan University and M.E from Anna University. She has obtained $\mathrm{PhD}$ from Manonmaniam Sundaranar University in 2009. She has been guiding various student projects in UG and PG. Currently she is guiding $8 \mathrm{PhD}$ scholars from VTU, Bharathiyar University and Karpagam University. The author received SMYSR award from VGST in 2015-16, K-FIST LEVEL I award from VGST and best teacher award from Atria IT. She has published 12 research papers in the fields of Image Processing and Artificial Intelligence. She is currently working as Professor and head of dept. CSE, Atria IT, Bangalore, India.

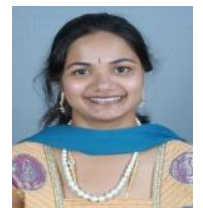

Ms. Pavithra P, had obtained B.E from Sri Venkateshwara college of Engineering, VTU and M.Tech from Nitte Meenakshi Institute of Technology, VTU. She has worked as Asst. Professor in REVA University for 8 years. The Author is currently pursuing $\mathrm{PhD}$ in VTU. The author has published 10 papers in International journals in the field of Image processing.

The author is currently pursuing PhD in VTU. 